\title{
Reflexões sobre o fazer pedagógico da Educação Física
}

\author{
Maria Isabel Brandão de Souza Mendes \\ Terezinha Petrucia da Nóbrega \\ José Pereira de Melo \\ Rosie Marie Nascimento de Medeiros \\ Grupo de Pesquisa Corpo e Cultura de Movimento da Universidade Federal do Rio \\ Grande do Norte - UFRN, Natal, RN, Brasil
}

\begin{abstract}
Resumo: Não é de hoje que se discute sobre a justificativa da existência e da permanência da Educação Física nas escolas brasileiras. Do final do século XIX até a contemporaneidade, decretos, leis e portarias reforçam a sua obrigatoriedade ou facultatividade, de acordo com os interesses de cada época. Com intuito de contribuir com esse debate, o objetivo desse ensaio é discutir sobre o trabalho docente dos professores de Educação Física no Ensino Fundamental, no sentido de vislumbrar possibilidades para a consolidação das práticas corporais nas escolas. Com base nas reflexões realizadas, identificamos que a visão dualista, e as políticas educacionais que associam a Educação Física a uma mera "atividade", dificultam o reconhecimento de que as práticas corporais são conhecimentos. Ao longo do texto, discutirmos sobre a importância da organização didática do conhecimento da Educação Física e ressaltamos a necessidade da participação dos professores de Educação Física nas tarefas pedagógicas das escolas, bem como da troca de experiências com os outros professores, com a equipe pedagógica, no sentido de propiciar a elaboração conjunta de atividades interdisciplinares, através do diálogo entre diferentes saberes, bem como a possibilidade de se registrar a organização didática da Educação Física, com vistas a colaborar com o desabrochar de relatos de experiências e pesquisas, que tenham como foco o cotidiano escolar.
\end{abstract}

Palavras-chave: Educação Física. Conhecimento. Corpo.

\section{Reflections about pedagogical making of the Physical Education}

\begin{abstract}
It is not of today that it is argued on the justification of the existence and the permanence of the Physical Education in the Brazilian schools. Of the end of the century XIX until the contemporary, decrees, laws and ordinances strengthen his obligatoriness or not, in accordance with the interests of each time. With intention to contribute with this debate, the objective of this assay is to argue about the teaching work of the professors of Physical Education in Elementary School, in the direction to glimpse possibilities for the consolidation of corporal practices in the schools. On the basis of the carried through reflections, we identify that the dualist vision, and the educational politics that associate the Physical Education to a "activity", make it difficult the recognition of that corporal practices are knowledge. Throughout the text, to argue about the importance of the didactic organization of the knowledge of the Physical Education and stand out the necessity of the participation of the professors of Physical Education in the pedagogical tasks of the schools, as well as the exchange of experiences with the other professors, with the pedagogical team, in the direction to propitiate the joint elaboration of interdisciplinaries activities, through the dialogue between different knowing, as well as the possibility of to register the didactic organization of the Physical Education, with sights to collaborate with unclasping of stories of experiences and researches, that have as focus the daily of the school.
\end{abstract}

Key Words: Physical Education. Knowledge. Body.

\section{Introdução}

Não é de hoje que se discute sobre a justificativa da existência e da permanência da Educação Física nas escolas brasileiras. Do final do século XIX até a contemporaneidade, decretos, leis e portarias reforçam a sua obrigatoriedade ou facultatividade, de acordo com os interesses de cada época. Para Souza Júnior (2005, p. 28):

\begin{abstract}
Os conflitos não se acabaram e não se acabarão. Muitos continuam, alguns com vieses mais recentes, como são os casos da presença, facultatividade ou mesmo ausência da Educação Física e da diversidade e até antagonismos de propostas pedagógicas atuais e outros que acompanham a trajetória de luta, de conquista, de reconhecimento, perfazendo a história deste componente curricular.
\end{abstract}

Por reconhecermos a relevância de abordar essa temática, nos dirigimos para o trabalho docente dos professores de Educação Física nas 
escolas, pois temos acompanhado a dificuldade da Educação Física ser reconhecida como componente curricular da Educação Básica, pelos depoimentos de vários professores que já participaram de cursos realizados pelo Núcleo de Formação Continuada para Professores de Artes e Educação Física - PAIDÉIA, que integra a Rede Nacional de Formação Continuada de Professores da Educação Básica, em parceria com o Ministério da Educação/Secretaria de Educação Básica-MEC/SEB.

Com o intuito de contribuir com esse debate, destacamos que o objetivo desse ensaio é discutir sobre o trabalho docente dos professores de Educação Física no Ensino Fundamental, no sentido de vislumbrar possibilidades para a consolidação das práticas corporais nas escolas.

Considerando que a Educação Física possui um conhecimento de natureza vivencial, um conhecimento pautado na expressão corporal, na linguagem dos gestos, do corpo em movimento, fazemos as seguintes indagações:

- As práticas corporais têm sido reconhecidas como conhecimentos no cotidiano escolar?

- Como a organização didática e a sistematização do conhecimento da Educação Física podem colaborar com a consolidação das práticas corporais no Ensino Fundamental?

Para discutir sobre essa temática, levaremos também em consideração as nossas experiências vividas. Relembramos alguns fragmentos dos anos de docência na Educação Básica. Recordamo-nos dos encontros no início dos anos letivos e de cada bimestre. Palestras e discussões sobre alguns estudiosos, como Piaget, Vygotsky ou Paulo Freire e sobre diversas temáticas, como a interdisciplinaridade e a avaliação formativa. Reuniões de planejamento, oficinas pedagógicas, momentos de reflexões e trocas de experiências com os professores de outras áreas do conhecimento, com os outros professores de Educação Física e com a equipe pedagógica das escolas. Momentos de reavaliar nossos conhecimentos e ações educativas e de pensar na formação dos nossos alunos. Desafios, descobertas de novas trilhas para reconstruir a prática. Resistências, inseguranças, dúvidas, entrosamentos e até estranhamentos.

Pensamos que atitudes e pensamentos que não consideram as práticas corporais como conhecimentos não podem ser considerados como naturais. Além de terem sido construídos dentro do contexto histórico de cada escola, também é importante refletirmos sobre as influências das políticas educacionais que vinculavam a Educação Física a uma mera "atividade" para a melhoria da aptidão física, para a busca do talento esportivo, como momento de recreação ou como instrumento para outras disciplinas. Outro fator importante para refletirmos é a influência da visão dualista para a educação. Alicerçada na concepção intelectualista, pautada nos pressupostos racionalistas da modernidade, concebe o corpo e os sentidos como erros, enganos ou como instrumento para a cognição, sendo então desconsiderados ou reconhecidos como acessórios no processo de produção do conhecimento, como destacam Mendes e Nóbrega (2004).

Por compreendermos que o movimento da história é dinâmico e que ao mesmo tempo em que apresenta rupturas, reconhecemos que há continuidades, acumula traços de épocas anteriores que são ressignificados. Ressaltamos, portanto, a necessidade de se buscar brechas em cada cotidiano escolar para contribuir com a superação dessa visão e com a construção de novas histórias.

Reconhecemos as diversas dificuldades do trabalho docente, mas gostaríamos de ressaltar a fala de Wittizorecki e Molina Neto (2005, p. 48) quando destacam que grande parcela de professores do ensino público:

Ante as limitações de suas condições de trabalho e a intensificação de suas atividades docentes - revela um sentimento de luta, de resistência, criatividade e esperança que os move frente a esses obstáculos. É nessa perspectiva que o professorado constrói suas estratégias de sobrevivência e resistência diante das dificuldades colocadas pelas condições sociais e materiais de escolarização.

Levando em consideração a possibilidade de superar obstáculos, de transgredir o instituído, ressaltamos a importância da participação dos professores de Educação Física nas tarefas pedagógicas realizadas por todos os professores das escolas. Pois, como destaca Castellani Filho (1998), graças à revolta dos profissionais da área que pressionaram deputados a intervirem na alteração do texto do Senador Darcy Ribeiro ${ }^{1}$, que a nova Lei de Diretrizes e Bases da

\footnotetext{
${ }^{1}$ Segundo Castellani Filho (1998), o texto do Senador Darcy Ribeiro abria espaço para a exclusão da Educação Física dos currículos, pelo seu caráter de não obrigatoriedade e por favorecer a promoção do esporte na escola como atividade extra-curricular e com fins lucrativos.
} 
Educação Nacional, promulgada em 1996, atrela a Educação Física à proposta pedagógica da escola. Considera-a como componente curricular da Educação Básica, possuidora de conhecimento a ser sistematizado, devendo participar das incumbências escolares.

\section{Educação Física: a cultura corporal e a cultura de movimento}

Pensar a Educação Física como componente curricular é reconhecer que, por ser um elemento da organização curricular da escola, é capaz de selecionar, organizar e sistematizar conhecimentos, com o intuito de contribuir com a formação cultural dos estudantes, juntamente com outros elementos da organização curricular, como destaca Souza Júnior (2006).

Na década de 90 do século $X X$ surgem como critérios organizadores do conhecimento da Educação Física o discurso da "cultura corporal" proposto por Soares et al. (1992) e da "cultura de movimento" proposto por Kunz (1991), que apesar de apresentarem especificidades, consideram que os conteúdos a serem ensinados nas aulas, não se restringem aos esportes, mas abarcam também os jogos, as danças, as ginásticas e as lutas, que se entrelaçam com o conhecimento do corpo. Essas manifestações são reconhecidas como fenômenos culturais, construídos e reconstruídos historicamente e contribuem com a superação de um fazer descontextualizado propiciando a desnaturalização do conhecimento da Educação Física e a intervenção crítica na realidade (BRACHT, 2005).

A cultura corporal ou cultura de movimento como critérios organizadores do conhecimento da Educação Física contribuem com a compreensão de que não é possível pensar no corpo e no movimento humano isolando os aspectos orgânicos dos aspectos simbólicos, haja vista que os códigos biológicos e culturais se entrelaçam, existindo a necessidade de aproximações com diversos saberes.

Nesse sentido, o conhecimento da Educação Física ao envolver a relação entre corpo, natureza e cultura é um conhecimento que vai sendo construído e reconstruído ao longo de nossas vidas e da história. Um conhecimento marcado pela linguagem sensível, que emerge do corpo e é revelada no movimento que é gesto, abarcando os aspectos orgânicos, culturais, sociais e históricos, abrangendo as diversas maneiras como o ser humano faz uso do seu corpo, ou seja, como cria e vivencia as técnicas corporais $^{2}$. Um conhecimento que permite a compreensão do mundo através do corpo em movimento no ambiente, cultura e história e capaz de despertar diferentes sentidos, tais como: saúde, lazer, cultura, auto-conhecimento, socialização e performance. A linguagem sensível é revelada através da movimentação do corpo no tempo e no espaço de cada indivíduo e da comunidade. Somos capazes de criar e recriar, e ao mesmo tempo em que nos expressamos, conseguimos nos comunicar (MENDES, 2002).

Considerando-se que os conteúdos de ensino como defende Zabala (2001), abarcam as dimensões conceituais, procedimentais e atitudinais e que o Ensino Fundamental II caracteriza-se pelo estabelecimento de reflexão sobre a realidade e pelo estabelecimento de relações e generalizações, pensemos no ensino da capoeira em uma das Unidades de ensino da Educação Física, tendo como preocupação além do fazer, o contextualizar e o apreciar. Além do aprendizado de técnicas corporais, como a ginga, a cocorinha e a meia lua de frente, partindo das experiências vividas dos alunos, do respeito aos limites de cada corpo e do corpo do outro, da percepção das alterações orgânicas ao vivenciar os ritmos da capoeira angola e regional, da possibilidade de novos usos do corpo durante 0 jogo da capoeira, existe a necessidade de se refletir sobre os significados e objetivos diversos sobre a vivência da capoeira, que varia conforme é praticada e por quem a pratica, seja numa roda realizada nas ruas, nas praias, numa apresentação para turistas ou nos Jogos Escolares.

Da ludicidade característica do jogo da capoeira para a lógica da esportivização dessa prática corporal, os sentidos de vivenciá-la podem ser diversos e o que para uma pessoa pode significar recontar tradições e expressar os valores de uma cultura, para outra, pode ter 0 sentido de cuidar do corpo, de se destacar num campeonato ou de adquirir novos conhecimentos. Outras reflexões também se fazem necessárias, como a história e evolução da capoeira, os instrumentos e cantos, o modo de inserção da

\footnotetext{
2 As técnicas corporais referem-se "as maneiras como os homens, sociedade por sociedade e de maneira tradicional, sabem servir-se de seus corpos" (MAUSS, 1974, p.211).
} 
capoeira na comunidade e a relação com outras regiões do país e do mundo, a possibilidade de se comunicar e de se relacionar através da linguagem dos gestos durante o jogo da capoeira, a possibilidade de apreciar o modo como a capoeira tem sido veiculada pelos meios de comunicação, pelos rituais de diferentes rodas de capoeira e os princípios éticos que as permeiam, dentre outras temáticas.

\section{Sistematização das práticas corporais}

Para falarmos sobre a organização didática e sistematização das práticas corporais no Ensino Fundamental, retomamos o estudo de Oliveira (1999, p. 10). O referido autor afirma que:

A Educação Física tem um papel fundamental no quadro da organização da cultura, desde que se disponha a compreendê-la em toda a sua amplitude. A partir das práticas corporais, da sua organização, da sistematização e da decodificação, existe um espaço pouco e mal explorado dentro da instituição escolar. Esse é o espaço de uma nova maneira de compreender as manifestações corporais como expressão inequívoca da cultura.

Organizar didaticamente e sistematizar as práticas corporais no Ensino Fundamental, tendo como base os discursos da cultura corporal ou cultura de movimento, além da compreensão das abordagens pedagógicas atreladas a esses conceitos, requer a compreensão de que a política de planejamento de uma aula de Educação Física, além de estar relacionada aos Planos Oficiais de Ensino, também está relacionada aos Planos das Escolas e aos Planos das Unidades de Ensino. Nesse sentido, cabe salientar que além das diretrizes expressas nos Parâmetros Curriculares Nacionais, é importante identificar a existência ou não de Propostas Curriculares dos Estados ou dos Municípios em que as escolas estão ligadas.

Se existem ... Que diretrizes podem servir de referência para contribuir com a elaboração dos Planos das Escolas, de acordo com as regiões específicas, as condições de cada escola e as condições dos alunos, no intuito de garantir a autonomia do trabalho docente?

Se não existem... Torna-se importante a reivindicação dos professores de Educação Física para a sua elaboração e mesmo com a necessidade de assessorias para a sua construção, é importante levar em consideração as experiências desses docentes. Uma Proposta Curricular da Educação Física que justifique o fazer pedagógico de seus professores e que tenha referenciais consistentes poderia colaborar para evitar certas distorções que tem surgido na área.

Ressaltamos também a importância da colaboração dos professores de Educação Física com a equipe pedagógica e com os outros professores, para a construção do Projeto Político Pedagógico, tendo em vista que este documento reflete a realidade de cada escola e expressa os princípios teórico-metodológicos, os objetivos, o tipo de organização e de avaliação da escola, além da compreensão de educação, de sociedade e de ser humano que se deseja formar. De acordo com Veiga (1998, p. 13):

O projeto pedagógico aponta um rumo, uma
direção, um sentido explícito para um
compromisso estabelecido coletivamente. O
projeto pedagógico, ao se constituir em
processo participativo de decisões, preocupa-se
em instaurar uma forma de organização do
trabalho pedagógico que desvele os conflitos e
as contradições, buscando eliminar as relações
competitivas, corporativas e autoritárias,
rompendo com a rotina do mando pessoal e
racionalizado da burocracia e permitindo as
relações horizontais no interior da escola.

Esse processo de construção coletiva é dinâmico e contínuo, pois é reconstruído conforme vai sendo avaliado e poderá contribuir para que os professores de Educação Física reflitam sobre a relação de suas aulas com os Planos de Unidades e os princípios norteadores do Projeto Político Pedagógico de cada escola, bem como sobre a possibilidade de dialogar com as outras áreas do conhecimento.

Ao realizarmos um Seminário na Disciplina Didática da Educação Física na Universidade Potiguar, em agosto de 2006, percebemos a dificuldade que alguns professores de Educação Física entrevistados apresentaram, no momento de identificar os princípios norteadores dos Projetos Político-Pedagógicos de suas escolas. Percebemos ainda, que muitas vezes os discursos expressos não se materializam nas ações pedagógicas, ou por não serem incorporados, ou por terem sido inseridos no Projeto Político Pedagógico só como necessidade de preenchimento de um papel, pois não reflete a realidade da escola. Como é o caso de uma instituição que se pauta no referencial da "cultura corporal" para fundamentar as aulas de Educação Física escolar, mas que tem como foco as práticas esportivas voltadas às competições, 0 
que nos faz perceber que a escola deixa de oferecer aos alunos o conhecimento de outras manifestações, além de não considerar a expressão corporal como linguagem e não ter a preocupação em oferecer práticas contextualizadas.

Pelo que observamos no referido estudo, o planejamento escolar ainda pode ser percebido pelo prisma de uma perspectiva tecnicista, em que não há reflexão sobre as ações docentes. Contrapondo-se a essa perspectiva destacamos a fala de Libâneo (1994), quando o autor mostra que a ação de planejar não se reduz ao preenchimento de formulários somente para controle administrativo. Para ele, a ação de planejar deve ser uma atividade consciente, embasadas em opções político-pedagógicas e nas situações didáticas da realidade.

A ação de planejar de forma consciente, com opções político- pedagógicas coerentes com um processo de democratização do ensino e que atenda a realidade escolar, poderá contribuir com o reconhecimento da Educação Física como componente curricular, pois como destaca Bracht (1992) a legitimação dessa prática social necessita de argumentos sólidos que a reconheçam como uma prática democrática.

O acompanhamento do planejamento, a utilização de recursos didáticos e espaços compatíveis para o desenvolvimento de seus conteúdos fazem parte do processo de organização do conhecimento da Educação Física. Além disso, inclui a definição da quantidade de conteúdos e do tempo necessário para estruturar a sua organização. Já os princípios que norteiam a prática pedagógica, os procedimentos metodológicos e avaliativos, bem como o tempo necessário para as aprendizagens dos alunos são elementos que contribuem com a sistematização do conhecimento da Educação Física (SOUZA JÚNIOR, 2007).

.Concordamos, portanto, com Souza Júnior (2007) quando defende que a legitimação pedagógica deve justificar os saberes para a formação de um ser humano que possa participar de forma crítica, solidária e criativa.

Ressaltamos, então, que organizar e sistematizar o conhecimento da Educação Física, de forma que os alunos compreendam que o ensino das práticas corporais poderá contribuir com a reflexão sobre o contexto em que está inserido, poderá contribuir com a justificativa dos saberes da Educação Física para a formação de um sujeito crítico e criativo, que saiba se relacionar com quem está a sua volta.

Destacamos a relevância da tese de Souza Júnior (2007), pela realização de uma discussão aprofundada sobre saberes escolares e o estabelecimento de relações com o currículo. Diante da investigação realizada com professores de escolas da Rede Municipal de Ensino do Recife, o autor propõe:

Superar os currículos prescritivos e
construirmos um currículo emancipatório, que
reconhece, propicia e solicita o potencial
produtor dos sujeitos educacionais
JÚNIOR, 2007, p. 316).

Ao defender um currículo emancipatório, o autor identifica que uma das dificuldades para a sistematização das práticas corporais nas escolas é a falta ou os precários recursos pedagógicos e ambientes específicos, pois estes têm definido a estruturação da prática pedagógica. Souza Júnior (2007) destaca ainda, que mesmo com a possibilidade de se utilizar diferentes metodologias, o ambiente específico e os recursos pedagógicos são considerados como condicionantes para a sistematização dos saberes escolares. O que o faz tecer críticas, pois defende que os professores não deveriam ficar a mercê dos recursos.

\section{A Educação Física escolar e os Esportes nas escolas}

É preciso pensar ainda, na relação complexa entre a Educação Física escolar e os Esportes nas escolas, pois com o fracasso esportivo do Brasil nas Olimpíadas de Sidney no ano 2000, o argumento utilizado para justificar a obrigatoriedade da Educação Física nas escolas brasileiras pelo imaginário social e reforçado por autoridades esportivas e educacionais foi à defesa de que a função da Educação Física é iniciar esportivamente futuros campeões. Como podemos perceber na pesquisa de Bracht et al. (2005) sobre o itinerário da Educação Física nas últimas três décadas do século $X X$ de um Colégio Estadual do Espírito Santo, a dispensa de atletas das aulas de Educação Física, que freqüentavam as equipes de treinamento, advém da década de 70 do século $X X$ e era justificada por uma compreensão de Educação Física pautada nos Planos Oficiais de Ensino, mais especificamente nos Planos de Desenvolvimento da Educação 
Física e do Desporto dos Governos Militares, que atribuíam à Educação Física a finalidade de melhorar a aptidão física e de iniciação esportiva, para preparar futuros atletas para as representações nacionais de elite.

Essa compreensão é fundamentada nos referenciais da Fisiologia do Exercício e ainda hoje, em várias regiões do país encontramos instituições públicas e privadas que ressignificam essas ações e não inserem as aulas de Educação Física dentro do horário escolar, reforçando-a como mera atividade.

Entendemos que a Educação Física não deveria se sustentar com bases nesses parâmetros, pois não coadunam com os critérios organizadores do conhecimento da área pautados na "cultura corporal" ou "cultura de movimento" e que trazem avanços significativos. Desse modo, os desafios são muitos e a participação dos professores de Educação Física nas tarefas pedagógicas de planejamento, execução e avaliação, considerando-se as especificidades de cada contexto escolar poderá contribuir para oferecer resistências às visões tradicionais da área e criar possibilidades para que as aulas de Educação Física sejam reconhecidas como espaços que permitam aos alunos à apropriação de uma diversidade de práticas corporais, reconhecidas como manifestações culturais, não apenas reproduzindo-as, mas de modo que os permitam a participar dessa construção e estabelecer reflexões coma realidade. Espaços que permitam aos alunos se comunicar e se relacionar através da expressão corporal, que despertem para o auto-conhecimento e os cuidados com a saúde. Definir o papel da Educação Física nas escolas, não requer o fim das Escolas de Esportes, nem das Equipes de Treinamento, pelo contrário, poderá despertar para a necessidade de maiores reflexões sobre as especificidades destas atividades no espaço escolar.

Destacamos ainda, que a participação dos professores de Educação Física nas tarefas pedagógicas das escolas poderá contribuir com o enfrentamento das problemáticas que surgem nas escolas através da troca de experiências com os outros professores da área.

Segundo Souza Filho (2007), não é só a Educação Física que passa por um processo contínuo e recheado de contradições por legitimação pedagógica com vistas a alcançar isonomia curricular. Com base no estudo com professores de Educação Física, Artes, Língua Portuguesa e Matemática de Escolas da Rede Municipal de Ensino do Recife, o autor ressalta que essa busca por isonomia curricular, não é sinônimo de igualdade, pois isso não seria possível, tendo em vista suas particularidades. Entretanto, mesmo com as peculiaridades de cada Disciplina, "há, na generalidade curricular, elementos que orientam diferentes disciplinas no cumprimento das atribuições e possibilidades pedagógicas e na conquista delas" (SOUZA FILHO, 2007, p. 326).

Com o reconhecimento das relações de tensões entre os saberes escolares por busca de reconhecimento na escola, destacamos que apesar das especificidades das Disciplinas, os elementos que as orientam para a realização das tarefas pedagógicas podem contribuir com os professores de Educação Física a pensar nos alunos que desejam formar, nas práticas corporais que serão tematizadas em cada bimestre ou trimestre no Ensino Fundamental I e no Ensino Fundamental II, levando-se em consideração os objetivos propostos para cada ciclo, os níveis de desenvolvimento dos alunos, os espaços e materiais disponíveis, as estratégias que serão utilizadas, o número de aulas destinadas a cada conteúdo abordado, a avaliação do processo de ensino-aprendizagem e a necessidade de replanejar e reorientar a ação pedagógica diante dos avanços e das dificuldades apresentadas, durante as trocas estabelecidas entre professor e aluno no processo de produção do conhecimento.

Pensar em modos de se relacionar com os alunos para a construção do trabalho docente, pois como destacam Wittizorecki e Molina Neto (2005), um dos obstáculos para a mudança da prática pedagógica está relacionada a representação de Educação Física que os alunos constroem, baseados nos significados pessoais, nas experiências vividas anteriormente com outros professores e em outras escolas e nas influências de outros espaços e instituições.

\section{Considerações Finais}

Durante a discussão sobre o trabalho docente de professores de Educação Física escolar, identificamos alguns pontos que dificultam 0 
reconhecimento de que as práticas corporais são conhecimentos, dos quais destacamos: a influência da visão dualista, bem como as influências das políticas educacionais que associam a Educação Física a uma mera "atividade".

Outro ponto identificado refere-se à dificuldade de sistematização das práticas corporais, em virtude da falta ou precariedade de ambiente específico e de recursos pedagógicos considerados apropriados para o desenvolvimento das aulas e que tem sido reconhecidos como condicionantes para a sistematização dos saberes escolares.

Destacamos, portanto, que a participação dos professores de Educação Física nas tarefas pedagógicas das escolas é fundamental para o reconhecimento da Educação Física como componente curricular que possui um conhecimento de natureza vivencial, um conhecimento pautado na expressão corporal, na linguagem dos gestos. Contribuindo assim, com a compreensão de que as práticas corporais são conhecimentos que são incorporados pelos alunos nas aulas de Educação Física. Conhecimentos encarnados, que ficam gravados na memória do corpo e que todos devem ter acesso, com o intuito de poder fazer uma leitura crítica da realidade e de contribuir com a formação cultural.

Portanto, ressaltamos a necessidade de participação dos professores de Educação Física desde a construção de uma Proposta Curricular da Disciplina que justifique o fazer pedagógico de seus professores e que tenha referenciais consistentes com uma prática social democrática até a participação na construção coletiva do projeto político-pedagógico da escola.

A participação dos professores de Educação Física nas tarefas pedagógicas das escolas poderá contribuir também, com a troca de experiências com os outros professores da escola, com a equipe pedagógica e propiciar a elaboração conjunta de atividades interdisciplinares, através do diálogo entre diferentes saberes e além de propiciar os registros da organização didática da Educação Física, poderá colaborar com o desabrochar de relatos de experiências e pesquisas, que tenham como foco o cotidiano escolar.
Além da participação no planejamento, execução e avaliação de sua intervenção educativa, outras atividades do trabalho docente ressaltadas por Wittizorecki e Molina Neto (2005), como a participação em reuniões, o atendimento aos responsáveis pelos alunos, a organização e participação em eventos promovidos pela escola, poderão contribuir com a consolidação das práticas corporais na educação básica e o reconhecimento da Educação Física como componente curricular.

Nesse sentido, para finalizar, relembramos o livro "Variações sobre o corpo", escrito pelo filósofo francês Michel Serres. As narrativas sobre as metamorfoses que o corpo pode realizar, partindo de suas experiências vividas, exaltam os diferentes sentidos postos pelo corpo em movimento. Desafios, êxtases, frustrações, prazeres e sofrimentos exibem a plasticidade corpórea, as possibilidades de criação do ser humano e de ser inacabado, a capacidade de atribuir signos, de se emocionar e de produzir conhecimento. Serres (2004) problematiza o dualismo ocidental, religa corpo e pensamento, natureza e cultura, animalidade e humanidade e nos faz refletir sobre a importância desses saberes nas escolas. Esse livro foi dedicado aos seus professores de educação física, treinadores e guias de montanhismo que o ensinaram a pensar.

\section{Referências}

BRACHT, V. Cultura corporal, cultura de movimento ou cultura corporal de movimento? In: SOUZA JÚNIOR, M. (Org.). Educação física escolar: teoria e política curricular, saberes escolares e proposta pedagógica. Recife: EDUPE, 2005. p 97-106.

BRACHT, V. et al. Itinerários da Educação Física na escola: o caso do Colégio Estadual do Espírito Santo. Revista Movimento, Porto Alegre, v.11, n.1, p. 09-21, jan./abr. 2005.

\section{BRACHT, V. Educação Física e aprendizagem} social. Porto Alegre: Magister, 1992.

\section{CASTELLANI FILHO, L. Política educacional e} educação física. São Paulo: Autores Associados, 1998.

KUNZ, E. Educação física: ensino e mudanças. ljuí: Unijuí, 1991.

LIBÂNEO, J. C. Didática. São Paulo: Cortez.1994. 
MAUSS, M. Sociologia e Antroplogia. Tradução de Lamberto Puccinelli. São Paulo: EPU/Edusp, 1974.

MENDES, M. I. B. S. Corpo e cultura de movimento: cenários epistêmicos e educativos. 2002. 137f. Dissertação (Mestrado em Educação) - Programa de Pós Graduação em Educação, Universidade Federal do Rio Grande do Norte, Natal, 2002.

MENDES, M. I. B. S.; NÓBREGA, T. P. Corpo, natureza e cultura: contribuições para a educação. Revista Brasileira de Educação. Rio de Janeiro, Associação Nacional de PósGraduação em Educação, n. 27, p. 125-137, setdez. 2004.

OLIVEIRA, M. A. T. Existe espaço para o ensino de educação física na escola básica? Pensar a Prática, Goiânia, v. 2, p. 119-135, jun. 1999.

\section{SERRES, M. Variações sobre o corpo.}

Tradução de Edgard de Assis Carvalho e Mariza Perassi Bosco. Rio de Janeiro: Bertrand Brasil, 2004.

SOARES, C. L; TAFFAREL, C. N. Z.; VARJAL, E.; CASTELLANI FILHO, L.; ESCOBAR, M. O.; BRACHT, V. Metodologia do ensino de educação física. São Paulo: Cortez, 1992.

SOUZA JÚNIOR, M. A educação física como componente curricular: polêmicas e desafios do passado e do presente. In: NÓBREGA, T. P. (Org.). Coleção cotidiano escolar: a educação física no ensino fundamental. Natal:

UFRN/Paidéia/Mec, 2006. p. 7-19.

SOUZA JÚNIOR, M. História da educação Física escolar no Brasil. In: NÓBREGA, T. P. (Org.). 0 ensino de educação física de $5^{\mathrm{a}}$ a $8^{\mathrm{a}}$ séries. Livro didático 3. Natal: Paidéia, 2005. p.13-32.

\section{SOUZA JÚNIOR, M. A constituição dos}

saberes escolares na educação básica. 2007. 354 f. Tese (Doutorado) - Curso de Educação, Departamento de Educação, Universidade Federal de Pernambuco, Recife, 2007.

VEIGA, I. P. A. Perspectivas para reflexão em torno do projeto político-pedagógico. In: VEIGA, I. P. A.; RESENDE, L. M. G. (Org.). Escola, espaço do projeto político-pedagógico. São Paulo: Papirus, 1998. p. 9-32.

WITTIZORECKI, E. S.; MOLINA NETO, V. O trabalho docente dos professores de Educação Física na Rede Municipal de Ensino de Porto Alegre. Revista Movimento, Porto Alegre, v.11, n.1, p. 47-70, jan./abr. 2005.
ZABALA, A. A prática educativa. Porto Alegre: Artmed, 2001.

Esse artigo foi apresentado no III Encontro Nacional de Ensino de Arte e Educação Física (ENAEF).

Endereço:

Maria Isabel Brandão de Souza Mendes

Rua das Algas 2190 Ponta Negra

Natal RN Brasil

59.090-410

Telefone: (84) 8816-4255

e-mail: isabelbsm1@gmail.com

Recebido em: 10 de julho de 2009. Aceito em: 05 de novembro de 2009.

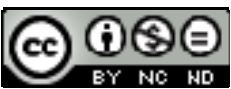

Motriz. Revista de Educação Física. UNESP, Rio Claro, SP, Brasil - elSSN: 1980-6574 - está licenciada sob Licença Creative Commons 